\title{
Rational thinking style, rejection of coronavirus (COVID-19) conspiracy theories/theorists, and compliance with mandated requirements: Direct and indirect relationships in a nationally representative sample of adults from the United Kingdom
}

Journal of Pacific Rim Psychology Volume 15: |-II (C) The Author(s) 2021 Article reuse guidelines: sagepub.com/journals-permissions DOI: I0.1 I77//83449092/1037385 journals.sagepub.com/home/pac @SAGE

\author{
Viren Swami ${ }^{1,2}$ and David Barron ${ }^{2}$
}

\begin{abstract}
Faced with the threat posed by the COVID-19 pandemic, many nations have mandated sets of requirements, such as social-distancing measures. However, compliance with such measures is likely to be shaped by a range of factors. Here, we proposed and tested a mediation model in which rejection of COVID-I9 conspiracy theories and/or theorists mediates the relationship between rational thinking style and compliance with mandated requirements. An online, nationally representative sample of the adult population in the United Kingdom $(N=520)$ completed a previously validated measure of rational thinking style, as well as novel measures of rejection of COVID-19 conspiracy theories/ theorists and compliance with mandated requirements. Intercorrelations between scores on all three measures were significant and positive. Mediation analysis indicated that rational thinking style and rejection of COVID-19 conspiracy theories/theorists, respectively, were directly associated with compliance, and that the mediated association was also significant. These results may have implications for practical policy aimed at promoting greater compliance with mandated requirements, including social distancing.
\end{abstract}

\section{Keywords}

coronavirus, COVID-19, conspiracy theories, rational thinking, social distancing

Received 29 November 2020; accepted 19 July 202I

\section{Introduction}

The coronavirus (COVID-19) pandemic presents a serious threat to physical and mental well-being worldwide. In response to the crisis, many governments have mandated a range of requirements, such as mask-wearing and social distancing. In 2020, for instance, the UK government shifted from a delay phase to a contain phase, which included a number of mandated social-distancing requirements (e.g., only leaving the home for food, health reasons, and work if individuals are unable to work from home; Cabinet Office, 2020). While the effectiveness of these measures and their impact on mental well-being continues to be discussed (e.g., Qiu et al., 2020; Torales et al., 2020), the available evidence from both the United Kingdom (Atchison et al., 2020) and elsewhere (e.g., Pedersen \& Favero, 2020; Zhang et al., 2020) indicates that individual ability and willingness to comply with social-

\footnotetext{
'School of Psychology and Sport Science, Anglia Ruskin University, Cambridge, UK

${ }^{2}$ Centre for Psychological Medicine, Perdana University, Kuala Lumpur, Malaysia
}

\section{Corresponding author:}

Prof. Viren Swami, School of Psychology and Sport Science, Anglia Ruskin University, East Road, Cambridge CBI IPT, UK.

Email: viren.swami@aru.ac.uk 
distancing measures are associated with a range of economic, sociopolitical, demographic, and psychological factors.

One potentially important psychological factor that may affect decisions to comply with mandated requirements is belief in conspiracy theories about COVID-19. Conspiracy theories about COVID-19-such as claims that it is caused by electromagnetic waves transmitted by $5 \mathrm{G}$ telephone masts or that governments are intentionally causing panic in order to introduce draconian population-control measures - have spread quickly since the pandemic began (Depoux et al., 2020; Kouzy et al., 2020), with about one in five respondents in the United States and United Kingdom believing in such theories (Geldsetzer, 2020). In turn, such beliefs may lead people to resort to potentially harmful remedies, to dismiss official guidance to prevent the spread of COVID-19, or to deliberately engage in risky behavior that spreads the virus (Pennycook et al., 2020). For example, it is conceivable that individuals who believe that COVID-19 is caused not by a virus but rather by electromagnetic waves may take fewer precautions to comply with social distancing and instead engage in action aimed at the perceived source of the threat (e.g., by setting fire to $5 \mathrm{G}$ telephone masts and thus endangering not just national infrastructure but also the lives of others; Waterson \& Hern, 2020).

Consistent with these arguments, some studies have reported a significant association between stronger belief in COVID-19 conspiracy theories and reduced compliance with mandated requirements (e.g., Bierwiaczonek et al., 2020; Fazio et al., 2021; Freeman et al., 2021; Rieger, 2020; but see Alper et al., 2021) and lower intention to reduce the spread of COVID-19 (Biddlestone et al., 2020). These findings are consistent with a large body of pre-pandemic research on the psychology of conspiracy theories (for reviews, see Douglas et al., 2017; Goreis \& Voracek, 2019; Swami \& Furnham, 2014), which has highlighted the link between belief in conspiracy theories and a range of negative health behaviors and intentions. For instance, stronger belief in conspiracy theories about influenza vaccinations (e.g., that it is a way to experiment on people without their knowledge) has been associated with less favorable attitudes toward the vaccine (Quinn et al., 2017) and lower intention to vaccinate (e.g., Hidiroglu et al., 2010; Lohiniva et al., 2014; Setbon \& Raude, 2010).

While it is likely that belief in COVID-19 conspiracy theories shaped attitudes and behaviors vis-à-vis mandated requirements, the available evidence also suggests that reducing the appeal of conspiracy theories can be very difficult, particularly among deeply convicted believers (e.g., Berinsky, 2017; Carey et al., 2020). Thus, rather than focusing on belief in
COVID-19 conspiracy theories, there may be greater value in focusing on those who do not believe in such conspiracy theories. Doing so may be practically useful, given that agent-based modelling has suggested that "immunizing" a fifth of a population from spreading conspiracy-framed narratives could mitigate against the negative effects of such misinformation during contagious disease outbreaks (Brainard \& Hunter, 2019). Of course, merely "not believing" in conspiracy theories may be insufficient, especially as it is possible that nonbelievers may become believers under certain circumstances (Douglas, 2021).

Instead, there may be value in adopting an alternative approach that supports individuals to critically evaluate the claims of conspiracy theorists, recognize and refute unsubstantiated claims, and ultimately adopt a stance of active rejection of conspiracy theories and the people who espouse them. Although we are not aware of any prior research that has focused on rejection of (as opposed to belief in) conspiracy theories, we suggest that such a framework may be particularly useful in the context of the COVID-19 pandemic. In this instance, misinformation and conspiracy theorizing about the pandemic has the potential to directly and negatively affect one's self-interests, as well as the interests of one's in-groups (e.g., by increasing the risk of infection). In such a scenario, it is possible that some individuals will develop and adopt a more critical attitudinal stance toward conspiracist beliefs, develop heightened affective responses (e.g., anger, disgust) toward conspiracy theorists, and support acts designed to reduce the spread of conspiracy theories or punish conspiracy theorists.

Of course, we do not suggest that all "nonbelievers" will adopt such a stance of active rejectionism. Nevertheless, measuring one's rejection of conspiracy theories may provide hitherto novel insights that will allow practitioners and policymakers to more effectively ensure compliance with mandated requirements. In this sense, it is possible that active rejection of conspiracy theories and conspiracy theorists will be associated with greater individual compliance with mandated requirements as a safeguard against perceived risktaking by others, particularly those who are perceived as conspiracy theorists (and who may be perceived as taking fewer precautions themselves). Certainly, this is a novel proposition, but there is some evidence that exposing individuals to rational counterarguments (Swami et al., 2013) - that is, providing individuals with valid reasons to reject conspiracy theorists - and ridiculing conspiracy theories (Orosz et al., 2016) are effective at reducing belief in conspiracy theories.

However, adopting a stance of active rejection is also likely to be cognitively effortful: such a stance requires an elaboration of one's own ideological commitment, a consideration of evidence that allows for a 
rejection of misinformation, and possibly a rehearsal of counterarguments. Such effortful cognition reflects what is sometimes called the System 2 process, or rational thinking style (sometimes also called analytic or reflective thinking style) within dual-process theory (e.g., Chaiken \& Trope, 1999; Evans \& Stanovich, 2013). Rational thinking is deliberative, cognitively demanding, and slow, and can be contrasted with System 1 processes or intuitive thinking, which is autonomous and fast. Recent research has suggested that individual differences in these thinking styles are associated with a range of beliefs (for a review, see Pennycook et al., 2015a), with greater rational/analytic thinking in particular being associated with significantly lower belief in conspiracy theories (Barron et al., 2018; Swami et al., 2014; van Prooijen, 2017), including COVID-19 conspiracy theories (Čavojová et al., 2021). Drawing on and extending these findings, we suggest here that a greater rational thinking style may provide the necessary basis for adopting a stance of active rejection of conspiracy theories and a negative view of people who espouse conspiracy theories.

Aside from indirectly affecting compliance with social-distancing measures via rejection of COVID-19 conspiracy theories, there is also a possibility that rational thinking style exerts a direct influence. This supposition is based on expectancy-value approaches (e.g., Ajzen, 1991), which suggests that health actions are the result of decision-making processes and reasoning geared toward goal attainment. For example, it is possible that the contemplation and premeditation that are hallmarks of rational thinking style focus attention on the risks of health (in)action, the relative costs and benefits of health-related behaviors, and the short and long consequences of health (in)action (Gerrard et al., 2008; Loewenstein et al., 2001). Such reasoning processes, in turn, are expected to facilitate decisionmaking that promotes positive health behaviors both for the self and for one's community, which here could involve the decision to comply with mandated requirements. Indeed, there is some emerging evidence to suggest that analytic thinking is positively associated with compliance with social-distancing measures and handwashing (Stanley et al., 2021; Teovanović et al., 2021). Additionally, individuals who prefer a rational thinking style may also have a greater sense of familiarity with scientific-medical consensus, which similarly increases compliance with social-distancing measures (see Plohl \& Musil, 2020).

\section{The present study}

Here, we suggest that there is value examining the extent to which both rejection of COVID-19 conspiracy theories/theorists and rational thinking style are related to compliance with mandated requirements to stop the spread of COVID-19. As such, we examined associations between these constructs in a sample of UK adults, recruited just over two weeks after the UK government announced a nationwide lockdown and mandated social-distancing measures in 2020. Specifically, we tested a mediation model in which, first, rational thinking style is significantly and directly associated with greater compliance with mandated requirements. Second, we also expected that rational thinking style would be significantly associated with greater rejection of COVID-19 conspiracy theories/theorists and, in turn, that rejection of such conspiracy theories/theorists would be significantly associated with greater compliance. A graphical depiction of our hypothesized model is presented in Figure 1.

\section{Method}

\section{Participants}

The participants of this study consisted of an online, nationally representative sample of adults from the United Kingdom $(N=520)$. Of the sample, 264

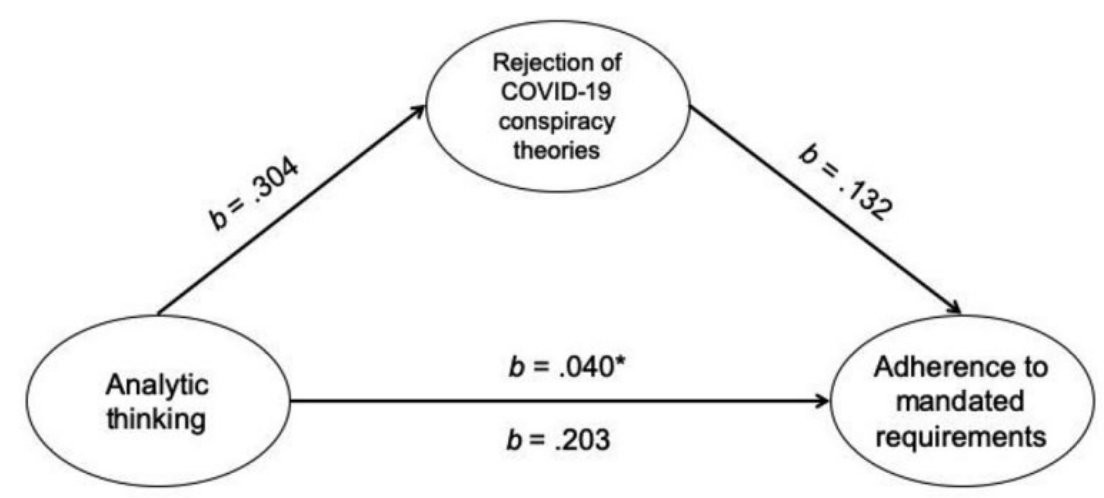

Figure I. Graphical representation of the hypothesized relationships, along with results of the mediation analysis (unstandardized coefficients between the variables); all ps $<.00 \mathrm{I}$ and the asterisk denotes an indirect effect. 
identified as women, 253 as men, and 3 as other, and the total sample ranged in age from 18 to 76 years $(M=45.85, S D=15.26)$. The majority of participants were British White $(81.0 \%$ ), while $8.5 \%$ were Asian/ British Asian, 4.8\% were Black/Black British, 3.8\% were of mixed race, and $1.9 \%$ were of other ancestry. In terms of educational qualifications, $21.2 \%$ had completed their General Certificates of Secondary Education (GCSEs), 21.3\% had an Advanced-Level (A-Level) qualification, $34.2 \%$ had an undergraduate degree, $18.1 \%$ had a postgraduate degree, $1.3 \%$ were still in full-time education, and $3.8 \%$ had some other qualification. In total, $12.1 \%$ self-reported that they were living on their own, $30.0 \%$ with a partner, $31.2 \%$ with a partner and children, $20.4 \%$ with their families, $3.8 \%$ with friends or housemates, and $2.5 \%$ in some other living arrangement. The majority of participants had not been tested and diagnosed with COVID$19(97.3 \%)$ and the majority also did not know anyone who had been tested and diagnosed $(73.1 \%)$.

\subsection{Materials}

2.2.I. Rejection of COVID-19 conspiracy theories. To assess rejection of COVID-19 conspiracy theories and critical attitudes toward COVID-19 conspiracy theorists, we designed a novel scale based on best-practice recommendations (Spector, 1992). Specifically, the first author initially defined and refined the constructs of interest through a reading of the available literature, before developing an initial 22-item pool. This item pool was then discussed between authors and consensually refined by rewording items to improve clarity and removing conceptually and semantically redundant items. The final item pool consisted of 18 items (see Table 1), which tap attitudinal and affective dispositions toward COVID-19 conspiracy theories and those who spread such theories, the negative consequences of such conspiracy theories, and support for efforts to minimize exposure to such conspiracy theories. All items were rated on a 7-point scale, ranging from 1 (strongly disagree) to 7 (strongly agree). We report on the factorial structure and internal consistency of this novel measure in the Results.

2.2.2. Rational thinking style. Participants were asked to complete the 12-item Rational Thinking Style subscale of the Rational/Experiential Multimodal Inventory (REIm; Norris \& Epstein, 2011). This subscale assesses individual differences in the tendency to solve problems through understanding of logical principles and the evaluation of evidence (sample item: "I enjoy problems that require hard thinking"). An overall score was computed as the mean of all 12 items, with higher scores

Table I. Item-level descriptive statistics and item-factor loadings for the novel measure of rejection of COVID-19 conspiracy theories.

\begin{tabular}{|c|c|c|c|}
\hline Item & M & $S D$ & $\begin{array}{l}\text { Factor } \\
\text { loading }\end{array}$ \\
\hline People who believe conspiracy theories about the epidemic are misguided. & 5.48 & 1.54 & .85 \\
\hline Conspiracy theories about the epidemic are only causing confusion and uncertainty. & 5.88 & 1.44 & .82 \\
\hline The sharing of conspiracy theories at this time is irresponsible. & 5.44 & 1.56 & .81 \\
\hline $\begin{array}{l}\text { I do not believe any of the conspiracy theories of the epidemic that I have come } \\
\text { across. }\end{array}$ & 5.48 & 1.69 & .81 \\
\hline This is not the time to be engaging in conspiracy theories about the epidemic. & 5.69 & 1.52 & .79 \\
\hline I think conspiracy theories about the epidemic have some truth to them (R). & 2.88 & 1.66 & -.77 \\
\hline Conspiracy theories about the epidemic usually do not make much sense. & 4.97 & 1.61 & .72 \\
\hline I feel angry when I see people sharing conspiracy theories about the epidemic. & 4.68 & 1.75 & .72 \\
\hline People who share conspiracy theories about the epidemic are untrustworthy. & 4.72 & 1.62 & .71 \\
\hline $\begin{array}{l}\text { The authorities should do more to clamp down on people who share conspiracy } \\
\text { theories about the epidemic. }\end{array}$ & 4.52 & 1.64 & .68 \\
\hline Conspiracy theories about the epidemic are a cause for concern. & 5.30 & 1.44 & .64 \\
\hline People who share conspiracy theories about the epidemic are acting selfishly. & 4.57 & 1.64 & .63 \\
\hline $\begin{array}{l}\text { People or organizations who share conspiracy theories about the epidemic should be } \\
\text { punished in some way. }\end{array}$ & 4.13 & 1.72 & .61 \\
\hline I find it disgusting that some people believe conspiracy theories about the epidemic. & 3.97 & 1.74 & .58 \\
\hline Conspiracy theories about the epidemic are endangering lives. & 5.14 & 1.62 & .55 \\
\hline $\begin{array}{l}\text { Conspiracy theories about the epidemic are making it difficult to stop the spread of } \\
\text { the coronavirus. }\end{array}$ & 4.09 & 1.73 & .41 \\
\hline Conspiracy theories about the epidemic are a cause of public disorder. & 4.22 & 1.63 & .39 \\
\hline Some people are spreading conspiracy theories for political or financial gain. & 4.99 & 1.48 & .28 \\
\hline
\end{tabular}

Note: (R) denotes an item that was reverse-coded. Items in bold are items that loaded onto the primary factor. 
Table 2. Item-level descriptive statistics and item-factor loadings for the novel measure of compliance with mandated requirements (as of April 9, 2020).

\begin{tabular}{|c|c|c|c|}
\hline Item & M & $S D$ & Factor loading \\
\hline Only going outside for food, health reasons, or work (only if you cannot work from home). & 6.65 & 0.68 & .82 \\
\hline Staying 2 meters ( 6 feet) away from other people when you have to go out. & 6.42 & 0.78 & .79 \\
\hline Washing your hands regularly and as soon as you return home. & 6.55 & 0.73 & .74 \\
\hline Not meeting other people, including family and friends, you do not share a home with. & 6.64 & 0.89 & .71 \\
\hline
\end{tabular}

reflecting a stronger rational thinking style. Scores on the REIm subscales have been shown to have adequate construct validity and internal consistency coefficients (Norris \& Epstein, 2011). In the present study, $\omega$ for scores on this subscale was $.93(95 \% \mathrm{CI}=.92, .94)$.

2.2.3. Compliance with mandated requirements. We asked participants to self-report their compliance to four activities adapted from the Cabinet Office's (2020) list of mandated requirements, which were in place on April 9-10, 2020, when the present data were collected (see Table 2). Items were rated on a 7-point scale ranging from 1 (completely disregarded) to 7 (completely adhered to). The factorial validity and internal consistency of this novel instrument are reported in the Results.

2.2.5. Demographics. Participants were asked to provide information about their gender identity, age, relationship status, ethnicity (based on categories from the last UK census), and educational attainment. We also asked participants whom they were residing with during the current social-distancing period $\left(1=N_{o}\right.$ one/single occupant, $2=$ Partner, $3=$ Partner and children, $\quad 4=$ Family/parents/guardians/siblings, $\quad 5=$ Friends/housemates, $6=$ Other), whether they had been tested and diagnosed with COVID-19 ( $1=$ No, $2=Y e s)$, and whether they knew anyone who had been tested and diagnosed with COVID-19 (1=No, $2=$ Yes, $3=$ Not sure).

\subsection{Procedures}

Our project was approved by the School research ethics panel at Anglia Ruskin University. All data were collected via the Prolific website, a crowdsourcing internet marketplace that allows individuals to complete academic surveys for monetary compensation, on April 9-10, 2020. The project was advertised as a study on "behaviors and attitudes during the coronavirus (COVID-19) pandemic" to mask the study's hypotheses and included an estimated duration (12 minutes). Cross-stratified quota sampling was used to obtain a nationally representative sample of the adult $(>18$ years) UK population based on gender identity, age, and ethnicity profiles at the last census. Prolific ID codes and IP addresses were examined to eliminate participants who took the survey more than once and who took a disproportionate amount of time to complete the survey. After providing digital informed consent, participants were directed to the scales described above, which were presented in a counterbalanced order in Qualtrics $^{\mathrm{TM}}$ (www.qualtrics.com). Demographic items were completed last. The questionnaire was anonymous and, in exchange for completion, participants were paid $£ 1.50$. All participants received debriefing information at the end of the survey. Our data are available in Open Science Framework at https://osf.io/8f72d/.

\section{Results}

\section{I. Factor analyses}

3.I.I. Factor analytic strategy. To examine the factor structure of responses to our two novel measures, we subjected the data to principal-axis exploratory factor analysis (EFA) in IBM SPSS Statistics v.24. The sample size met requirements for EFA based on item communalities (Worthington \& Whittaker, 2006), as well as assumptions for EFA based on item distributions, average item correlations, and item-total correlations (Clark \& Watson, 1995). Data factorability was assessed using the Kaiser-Meyer-Olkin (KMO) measure of sampling adequacy (which should ideally be $>$.80) and Bartlett's test of sphericity (which should be significant). Following Tabachnick and Fidell's (2007) recommendation, we applied a promax rotation, an oblique rotation method that assumes any emergent factors will be correlated. Factor extraction was based on the results of parallel analysis (Hayton et al., 2004), which reduces the likelihood of factor over-retention compared to other commonly used extraction methods (Velicer et al., 2000). Parallel analysis works by creating a random dataset with the same number of cases and variables as the actual dataset. Factors in the actual data are only retained if their eigenvalues are greater than the eigenvalues from the random data (Hayton et al., 2004). Item retention was based on Comrey and Lee's (1992) recommendation that items with "fair" loadings (i.e., $\geq .33$ ) should be retained. 


\section{I.2. Rejection of COVID-I 9 conspiracy theories. The KMO} measure of sampling adequacy $(\mathrm{KMO}=.95)$ and Bartlett's test of sphericity, $\chi^{2}(153)=5965.89$, $p<.001$, both indicated that these data were factorable. The results of the EFA revealed two factors with $\lambda>1.0$, though inspection of the scree plot suggested a single primary factor with a steep cut-off to a secondary factor. In addition, parallel analysis indicated that only a single factor should be extracted: only the first factor from the actual data had $\lambda$ greater than the criterion $\lambda$ generated from the random data (i.e., 9.26 [actual data] compared to 7.53 [random data]). The second factor derived from the actual data had an $\lambda$ that was lower than the corresponding criterion $\lambda$ generated from the random data (i.e., 1.48 [actual data] compared to 1.99 [random data]). As such, we retained a single factor, which explained $51.2 \%$ of the common variance. As reported in Table 1, all but one item ("Some people are spreading conspiracy theories for political or financial gain") had factor loadings that were minimally fair by Comrey and Lee's (1992) standards. We, therefore, computed a total score by taking the mean of the remaining 17 items. Omega for this total score was $.94(95 \% \mathrm{CI}=.93, .95)$.

3.I.3. Compliance with mandated requirements. The KMO measure of sampling adequacy $(\mathrm{KMO}=.78)$ was slightly below adequacy, but Bartlett's test of sphericity, $\chi^{2}(153)=520.83, p<.001$, was significant, so we proceeded with the factor analysis. The results revealed a single factor with $\lambda=2.63$, explaining $58.6 \%$ of the common variance. All four items loaded onto this factor (see Table 2), so we computed a total score by taking the mean of all items. Internal consistency for scores on this measure was adequate, with $\omega=.78$ $(95 \% \mathrm{CI}=.75, .81)$.

\subsection{Mediation analysis}

Bivariate correlations between analytic thinking, rejection of COVID-19 conspiracy theories/theorists, and compliance with mandated requirements are reported in Table 3. Given the observed statistically significant relationships between these variables, we used the PROCESS for IBM SPSS Statistics macro developed by Hayes (2018) to test the hypothesized mediation model. The bootstrap procedure embedded in the macro was used, drawing on 5,000 bootstrap samples from the dataset. Both direct and indirect effects were estimated, with the latter considered statistically significant at the .05 level of the $95 \%$ CI when the CI does not include zero. Using compliance with mandated requirements as the outcome variable, rational thinking style showed a significant indirect effect through rejection of COVID-19 conspiracy theories/theorists,
Table 3. Descriptive statistics and bivariate correlations between all variables included in the present study.

\begin{tabular}{llll}
\hline & $(1)$ & $(2)$ & $(3)$ \\
\hline $\begin{array}{l}\text { (I) Compliance with mandated } \\
\text { requirements }\end{array}$ & & $.3 I^{* *}$ & $.3 I^{* *}$ \\
(2) Rejection of COVID-19 & & & $.19 * *$ \\
$\quad$ conspiracy theories & & & \\
(3) Analytic thinking & & & \\
M & 6.56 & 4.90 & 3.71 \\
SD & 0.59 & 1.17 & 0.74 \\
\hline
\end{tabular}

Note: $\mathrm{N}=520 ; *_{\mathrm{p}}<.001$.

$B=.051, \mathrm{SE}=.015,95 \%$ CI $(.024, .083)$. The direct effect of rational thinking style on compliance in this model was significant $t(517)=6.24, \quad B=.256$, $\mathrm{SE}=.033, p<.001,95 \%$ CI $(.140, .267)$. Likewise, the direct effect of rational thinking style on rejection of COVID-19 conspiracy theories/theorists was significant, $t(518)=4.46, B=.192, \mathrm{SE}=.068, p<.001,95 \%$ CI $(.170, .438)$, as was the direct effect of rejection of COVID-19 conspiracy theories/theorists on compliance, $t(517)=6.41, B=.263, \mathrm{SE}=.021, p<.001,95 \%$ CI $(.092, .172)$. Unstandardized path coefficients are included in Figure 1. In addition, the model remained stable and all paths were significant when we included education, gender identity, and age as covariates. ${ }^{1}$

\section{Discussion}

In the present study, we hypothesized that rational thinking style would be directly associated with greater compliance with mandated requirements that were in place in the United Kingdom in early April 2020, as well as indirectly via the rejection of COVID-19 conspiracy theories/theorists. The results of our mediation analysis supported our hypotheses: in a sample of adults in the United Kingdom, we found evidence of significant direct and indirect associations between rational thinking style and compliance. Put differently, our results suggest that individuals who, in the parlance of dual-process theory (e.g., Chaiken \& Trope, 1999; Evans \& Stanovich, 2013), utilize System 2 processes to a greater extent - characterized by deliberative, cognitively demanding, and slow cognitive styles - were more likely to comply with mandated requirements. Additionally, they were also more likely to reject COVID-19 conspiracy theories/theorists, which in turn was associated with greater compliance.

Our finding of a significant positive association between rational thinking style and compliancemandated requirements is consistent with the findings of two previous studies, where analytic thinking - as measured using the Cognitive Reflection Test-was associated with greater propensity to socially distance 
and hand-wash (Stanley et al., 2021; Teovanović et al., 2021). Our hypothesizing in this regard was broadly derived from expectancy-value approaches to health behaviors (e.g., Ajzen, 1991), which suggest that health-related intentions and actions are typically the result of rational decision-making processes. More specifically, we suggest that a tendency to adopt a rational thinking style may focus attention on the risks of COVID-19 and the benefits of complying with mandated requirements not just for the self, but possibly also for close others and the wider community. Indeed, there is some evidence that COVID-19 risk perception was significantly associated with greater compliance with social-distancing measures in adults (Wise et al., 2020) and adolescents (Oosterhoff \& Palmer, 2020), and it is possible that rational thinking style may facilitate greater and more accurate assessments of risk probability (e.g., see Leikas et al., 2007). Individuals who adopt a rational thinking style may also have a greater sense of familiarity with scientific-medical consensus (Plohl \& Musil, 2020), better ability to detect misinformation (Pennycook \& Rand, 2020), and are possibly more altruistic (Arechar et al., 2017), all of which likely promotes greater compliance with mandated requirements.

Beyond the direct association, our results also indicated that rational thinking style was indirectly associated with compliance via rejection of COVID-19 conspiracy theories and negative perceptions of conspiracy theorists. The first part of this mediated pathway is consistent with previous work indicating that analytic thinking is significantly associated with lower belief in COVID-19 conspiracy theories (Čavojová et al., 2021) and that a rational thinking style is associated with lower belief in conspiracy theories more generally (Barron et al., 2018; Swami et al., 2014; van Prooijen, 2017). For example, previous experimental work has shown that it may be possible to reduce belief in conspiracy theories by priming analytic/rational thinking (Swami et al., 2014). However, one difference between our work and that of previous studies is the fact that we focused not on low belief in conspiracy theories, but rather a more active rejection of COVID19 conspiracy theories and/or conspiracy theorists. That is, our results suggest that the deliberation, contemplation, and premeditation involved in a rational thinking style may provide individuals with the cognitive tools to adopt a more critical stance toward both COVID-19 conspiracy theories and develop more negative attitudinal stances toward conspiracy theorists.

In turn, rejection of COVID-19 conspiracy theories/ theorists was both directly associated with compliance and also mediated the association between rational thinking style and compliance. In a very general sense, these findings can be considered to be analogous to studies showing that stronger belief in COVID-19 conspiracy theories is associated with reduced compliance with mandated requirements (e.g., Bierwiaczonek et al., 2020; Fazio et al., 2021; Freeman et al., 2021; Rieger, 2020; see also Biddlestone et al., 2020). The novelty of our work, however, lies in our measurement of COVID-19 conspiracism: rather than conceptualizing belief along a continuum of strength (i.e., passive disbelief to endorsement), our approach was based on more active rejection of COVID-19 conspiracy theories and those who espouse such theories. This resulted in the construction of a unidimensional scale that measured explicit rejection of COVID-19 conspiracy theories, negative attitudinal and affective responses toward people who spread such conspiracy theories, beliefs that such conspiracy theories have negative consequences, and support for efforts to minimize exposure to such conspiracy theories. Thus, it may be that the conceptualization of active rejection of conspiracy theories/theorists offers a complementary approach for examining the outcomes of conspiracy theories.

Two other findings from the present study are worth highlighting. First, it was notable that mean responses on the measure of compliance with mandated requirements at the time this study was conducted was very high. This is consistent with reports of high rates of compliance with social-distancing mandates in other European nations (e.g., Briscese et al., 2020), although it should be noted that our results are time-limited (i.e., they do not say anything about how compliance may or may not change over time). Second, our results were robust even after controlling for key participant demographics, namely gender identity, age, and education. Controlling for the last variable may be particularly important given previous research suggesting people with higher education are less likely to believe in conspiracy theories (see van Prooijen, 2017). Importantly, however, we did not measure and control for cognitive ability, which is notable given that cognitive ability is associated with both the tendency to adopt a rational thinking style and to think analytically (see Pennycook \& Ross, 2016) regarding belief in conspiracy theories (Swami et al., 2011). Indeed, research by Ståhl and van Prooijen (2018) has suggested that the link between analytic thinking and skepticism toward unfounded beliefs may be underpinned by cognitive ability.

Certainly, future research would benefit from extending our results by including measures of cognitive ability, although it should be noted that reported associations with belief in conspiracy theories have sometimes been weak (e.g., Stieger et al., 2013). Future work would also benefit from including a wider array of factors that may be associated with either belief in, or rejection of, COVID-19 conspiracy theories. For example, emerging research has suggested 
that greater anxiety and perceived lack of control were significantly associated with belief in COVID-19 conspiracy theories in an online sample of Slovak adults (Srol et al., 2020). It may also be useful to include measures of other relevant psychological constructs, such as perceived risk (see Dunning \& Pownall, 2020) and support for governmental responses to pandemic crises (e.g., Conway et al., 2020), to better account for some of our hypothesizing. Of course, it should also be noted that the present research was centrally focused on psychological factors that are associated with compliance, but individual ability and willingness to comply with social-distancing measures are also likely to be affected by economic, sociopolitical, and temporal factors (e.g., Atchison et al., 2020; Zhang et al., 2020).

In terms of the latter, it is worth repeating that our findings may be limited to a particular time-point in the containment phase of the United Kingdom's strategy for stopping the spread of COVID-19 and thus may have limited generalizability during other phases or to other nations. Also of note, the cross-sectional nature of data means that causational conclusions should be drawn with extreme caution. While we have interpreted our results in line with extant theorizing, it is also possible that bidirectional links exist (e.g., between rational thinking style and rejection of conspiracy theories/ theorists). Finally, while we have no reason to believe that our measure of active rejectionism of COVID-19 conspiracy theories/theorists lacks validity (e.g., given the significant association with analytic thinking), it would be useful in future research to assess construct validity more fully. This could be achieved, for example, by examining associations between scores on our novel measure and scores on generic measures of belief in conspiracy theories (for a review of relevant measures, see Swami et al., 2017). Doing so may be particularly important given that our novel measure, although unidimensional, measures a number of different elements that we globally consider to be reflective of rejectionism.

These limitations notwithstanding, the present results suggest that individual differences in the disposition to think rationally may help shape compliance with mandates to stop the spread of COVID-19 both directly and via rejection of conspiracy theories/theorists. Although the question of what promotes analytic/ rational thinking has been discussed widely in the past decade (e.g., Evans \& Stanovich, 2013; Pennycook et al., 2015b), there remains a need to better understand how the promotion of analytic/rational thinking can be best achieved outside the laboratory. This question takes on added urgency under conditions of mandated social distancing, where novel communication strategies will be required and individual voluntarism to engage with interventions may be important. Aside from such methods, it will also be important to provide citizens with the tools to more effectively and efficiently combat the spread of COVID-19 conspiracy theories, such as by nudging citizens toward trusted sources of information (Gostin et al., 2020; Wiederhold, 2020) or regulating available health information (Cuan-Baltazar et al., 2020). Doing so may be important not only to motivate greater compliance with mandated requirements, but also to prevent negative outcomes of conspiracy theorizing during the COVID-19 pandemic.

\section{Data availability}

The data that support the findings of this study are openly available in Open Science Framework at https://osf.io/8f72d/.

\section{Declaration of conflicting interests}

The author(s) declared no potential conflicts of interest with respect to the research, authorship, and/or publication of this article.

\section{Funding}

The author(s) disclosed receipt of the following financial support for the research, authorship, and/or publication of this article: This research was supported by a grant made to the first author from Perdana University (grant number: PUCPM-001).

\section{Note}

1. When education, gender identity, and age were included as covariates, analytic thinking exerted a significant indirect effect on compliance via rejection of COVID-19 conspiracy theories, $B=.046, \mathrm{SE}=.014,95 \% \mathrm{CI}(.019, .075)$. The direct effect of analytic thinking on compliance with mandated requirements was significant $t(514)=7.12, B=.283$, $\mathrm{SE}=.032, p<.001,95 \% \mathrm{CI}(.162, .286)$, as was the direct effect of analytic thinking on rejection of COVID-19 conspiracy theories, $t(515)=4.31, \quad B=.188, \quad \mathrm{SE}=.069$, $p<.001,95 \%$ CI $(.162, .433)$, and the direct effect of rejection of COVID-19 conspiracy theories on compliance, $t(514)=6.15, \quad B=.242, \quad \mathrm{SE}=.020, \quad p<.001, \quad 95 \% \quad \mathrm{CI}$ $(.083, .160)$.

\section{References}

Ajzen, I. (1991). The theory of planned behavior. Organizational Behavior and Human Decision Processes, 50, 179-211.

Alper, S., Bayrak, F., \& Yilmaz, O. (2021). Psychological correlates of COVID-19 conspiracy beliefs and preventive measures: Evidence from Turkey. Current Psychology. Advanced online publication, https://doi.org/10.1007/ s12144-020-00903-0.

Arechar, A., Kraft-Todd, G., \& Rand, D. (2017). Turking overtime: How participant characteristics and behavior 
vary over time and day on Amazon Mechanical Turk. Journal of Economic Science Association, 3, 1-11. https:// doi.org/10.1007/s40881-017-0035-0.

Atchison, J., Bowman, L., Vrinten, C., Redd, R., Pristera, P., \& Eaton, J. (2020, April 3). Perceptions and behavioural responses of the general public during the COVID-19 pandemic: A cross-sectional survey of $U K$ adults. MedRxiv. https://doi.org/10.1101/2020.04.01.20050039.

Barron, D., Furnham, A., Weis, L., Morgan, K. D., Towell, T., \& Swami, V. (2018). The relationship between schizotypal facets and conspiracist beliefs via cognitive processes. Psychiatry Research, 259, 15-20. https://doi.org/10. 1016/j.psychres.2017.10.001.

Berinsky, A. A. J. (2017). Rumors and health care reform: Experiments in political misinformation. British Journal of Political Science, 47, 241-246. https://doi.org/ S0007123415000186.

Biddlestone, M., Green, R., \& Douglas, K. M. (2020). Cultural orientation, power, belief in conspiracy theories, and intentions to reduce the spread of COVID-19. British Journal of Social Psychology, 59(3), 663-673. https://doi. org/10.1111/bjso.12397.

Bierwiaczonek, K., Kunst, J. R., \& Pich, O. (2020). Belief in COVID-19 conspiracy theories reduces social distancing over time. Applied Psychology: Health and Well-Being, 12(4), 1270-1285. https://doi.org/10.1111/aphw.12223.

Brainard, J., \& Hunter, P. R. (2019). Misinformation making a disease outbreak worse: Outcomes compared for influence, monkeypox, and norovirus. Simulation, 96(4), 365-374. https://doi.org/10.1177/0037549719885021.

Briscese, G., Lacetera, N., Macis, M., \& Tonin, M. (2020). Compliance with COVID-10 social-distancing measures in Italy: The role of expectations and duration (NBER Working Paper No. 26916). National Bureau of Economic Research. http://www.nber.org/papers/w26916.

Cabinet Office. (2020, April 9). Coronavirus outbreak FAQs: What you can and can't do. https://www.gov.uk/govern ment/publications/coronavirus-outbreak-faqs-what-youcan-and-cant-do/coronavirus-outbreak-faqs-what-youcan-and-cant-do.

Carey, J. M., Chi, V., Flynn, D. J., Nyhan, B., \& Zeitzoff, T. (2020). The effects of corrective information about disease epidemics and outbreaks: Evidence from Zika and yellow fever in Brazil. Science Advances, 6, eaaw7449. https://doi. org/10.1126/sciadv.aaw7449.

Čavojová, V., Šrol, J., \& Ballová Mikušková, E. (2021). How scientific reasoning correlates with health-related beliefs and behaviors during the COVID-19 pandemic. Journal of Health Psychology. Advanced online publication. https://doi.org/10.1177/1359105320962266.

Chaiken, S., \& Trope, Y. (1999). Dual-process theories in social psychology. New York, NY: Guilford Press.

Clark, L. A., \& Watson, D. (1995). Constructing validity: Basic issues in objective scale development. Psychological Assessment, 7(3), 309-319. https://doi.org/10.1037/10403590.7.3.309.

Comrey, A. L., \& Lee, H. B. (1992). A first course in factor analysis. London: Lawrence Erlbaum.
Conway, L., Woodard, S. R., \& Zubrod, A. (2020, April 8). Social psychological measurements of COVID-19: Coronavirus perceived threat, government response, impact and experiences questionnaires. PsyArXiv. https://doi.org/ 10.21234/osf.io/z2x9a.

Cuan-Baltazar, J. Y., Muñoz-Perez, M. J., Robledo-Vega, C., Pérez-Zepeda, M. F., \& Soto-Vega, E. (2020). Misinformation of COVID-19 on the Internet: Infodemiology study. JMIR Public Health and Surveillance, 6(2), e18444. https://doi.org/10.2196.18444.

Depoux, A., Martin, S., Karafillakis, E., Preet, R., WilderSmith, A., \& Larson, H. (2020). The pandemic of social media panic travels faster than the COVID-19 outbreak. Journal of Travel Medicine. Advanced online publication. https://doi.org/10.1093/jtm/taaa031.

Douglas, K. M. (2021). COVID-19 conspiracy theories. Group Processes and Intergroup Relations, 24(2), 270-275. https://doi.org/10.1177/1368430220982068.

Douglas, K. M., Sutton, R. M., \& Chichoka, A. (2017). The psychology of conspiracy theories. Current Directions in Psychological Science, 26(6), 538-542. https://doi.org/10. 1177/0963721417718261.

Dunning, A., \& Pownall, M. (2020, April 7). Dispositional and situational attribution of COVID-19 risk: A content analysis of response typology. PsyArXiv. https://doi.org/ 10.31234/osf.io.czskd.

Evans, J. St. B. T., \& Stanovich, K. E. (2013). Dual-process theories of higher cognition: Advancing the debate. Perspectives in Psychological Science, 8(3), 223-241. https://doi.org/10.1177/1745691612460685.

Fazio, R. H., Ruisch, B. C., Moore, C. A., Granados Samayoa, J. A., Boggs, S. T., \& Ladanyi, J. T. (2021). Who is (not) complying with the U.S. social distancing directive and why? Testing a general framework of compliance with virtual measures of social distancing. PLoS ONE, 16(2), e0247520. https://doi.org/10.1371/journal. pone. 0247520 .

Freeman, D., Waite, F., Rosebrock, L., Petit, A., Causier, C., East, A., Jenner, L., Teale, A. L., Carr, L., Mulhall, S., Bold, E., \& Lambe, S. (2021). Coronavirus conspiracy beliefs, mistrust, and compliance with government guidelines in England. Psychological Medicine. Advanced online publication. https://doi.org/10.1017/S0033291720001890.

Geldsetzer, P. (2020, March 27). Knowledge and perceptions of coronavirus disease 2019 among the general public in the United States and United Kingdom: A cross-sectional online survey. MedRxiv. https://doi.org/10.1101/2020.03. 13.20035568.

Gerrard, M., Gibbons, F. X., Houlihan, A. E., Stock, M. L., \& Pomery, E. A. (2008). A dual-process approach to health risk decision making: The prototype willingness model. Developmental Review, 28(1), 29-61. https://doi. org/10.1016/j.dr.2007.10.001.

Goreis, A., \& Voracek, M. (2019). A systematic review and meta-analysis of psychological research on conspiracy beliefs: Field characteristics, measurement instruments, and associations with personality traits. Frontiers in Psychology, 10, 205. https://doi.org/10.3389/fpsyg.2019. 0020. 
Gostin, L. O., Friedman, E. A., \& Wetter, S. A. (2020). Responding to COVID-19: How to navigate a public health emergency legally and ethically. Hastings Center Report. Advanced online publication. https://doi.org/10. 1002/hast. 1090.

Hayes, A. F. (2018). Introduction to mediation, moderation, and conditional process analysis: A regression-based approach (2nd ed.). New York, NY: Guilford Press.

Hayton, J. C., Allen, D. G., \& Scarpello, V. (2004). Factor retention decisions in exploratory factor analysis: A tutorial on parallel analysis. Organizational Research Methods, 7(2), 191-205. https://doi.org/10.1177/1094428104263675.

Hidiroglu, S., Ay, P., Topuzoglu, A., Kalafat, C., \& Karavus, M. (2010). Resistance to vaccination: The attitudes and practices of primary healthcare workers confronting the H1N1 pandemic. Vaccine, 28(51), 8120-8124. https://doi. org/10.1016/j.vaccine.2010.09.104.

Kouzy, R., Abi Jaoude, J., Kraitem, A., El Alam, M. B., Karam, B., Adib, E., Zarka, J., Traboulsi, C., Akl, A. W., \& Baddour, K. (2020). Coronavirus goes viral: Quantifying the COVID-19 misinformation epidemic on Twitter. Cureus, 12(3), e7255. https://doi.org/10.7759/ cureus. 7255 .

Leikas, S., Lindeman, M., Roininen, K., \& Lähteenmäki, L. (2007). Food risk perceptions, gender, and individual differences in avoidance and approach motivation, intuitive and analytic thinking styles, and anxiety. Appetite, 48(2), 232-240. https://doi.org/10.1016/j.appet.2006.09.009.

Loewenstein, G. F., Weber, E. U., Hsee, C. K., \& Welch, N. (2001). Risk as feelings. Psychological Bulletin, 127(2), 267-286. https://doi.org/10.1037/0033-2909.127.2.267.

Lohiniva, A.-L., Barakat, A., Dueger, E., Restrepo, S., \& El Aouad, R. (2014). A qualitative study of vaccine acceptability and decision making among pregnant women in Morocco during the A (H1N1) pdm09 pandemic. PLoS ONE, 9(10), e96244. https://doi.org/10.1371/jour nal.pone.0096244.

Marinthe, G., Brown, G., Delouvée, S., \& Jolley, D. (2020). Looking out for myself: Exploring the relationship between conspiracy mentality, perceived personal risk, and COVID-19 prevention measures. British Journal of Health Psychology, 25(4), 957-980. https://doi.org/10. 1111/njhp. 12449.

Norris, P., \& Epstein, S. (2011). An experiential thinking style: Its facets and relations with objective and subjective criterion measures. Journal of Personality, 79, 1043-1079. https://doi.org/10.1111/j.1467-6494.2011.00718.x.

Oosterhoff, B., \& Palmer, C. (2020, March 23). Psychological correlates of news monitoring, social distancing, disinfecting, and hoarding behaviors among US adolescents during the COVID-19 pandemic. PsyArXiv. https://doi.org/10. 31234/osf.io/rpcy4.

Orosz, G., Krekó, P., Paskuj, J., Tóth-Király, I., Böthe, B., \& Roland-Lévy, C. (2016). Changing conspiracy beliefs through rationality and ridicule. Frontiers in Psychology, 7, 1525. https://doi.org/10.3389/fpsyg.2016.01525.

Pedersen, M. J., \& Favero, N. (2020). Social distancing during the COVID-19 pandemic: Who are the present and future noncompliers? Public Administration Review, 80(5), 805-814. https://doi.org/10.1111/puar.13240.

Pennycook, G., Fugelsang, J. A., \& Koehler, D. J. (2015a). Everyday consequences of analytic thinking. Current Directions in Psychological Science, 24(6), 425-432. https://doi.org/10.1177/0963721415604610.

Pennycook, G., Fugelsang, J. A., \& Koehler, D. J. (2015b). What makes us think? A three-stage dual-process model of analytic engagement. Cognitive Psychology, 80, 34-72. https://doi.org/10.1016/j.cogpsych.2015.05.001.

Pennycook, G., McPhetres, J., Zhang, Y., \& Rand, D. G. (2020, March 18). Fighting COVID-19 misinformation on social media: Experimental evidence for a scalable accuracy nudge intervention. PsyArXiv. https://doi.org/ 10.31234/osf.io/uhbk9.

Pennycook, G., \& Rand, D. G. (2020). Who falls for fake news? The roles of bullshit receptivity, overclaiming, familiarity, and analytic thinking. Journal of Personality, 88(2), 185-200. https://doi.org/10.1111/jopy.12476.

Pennycook, G., \& Ross, R. M. (2016). Commentary: Cognitive reflection vs. calculation in decision making. Frontiers in Psychology, 7(9). https://doi.org/10.3389/ fpsyg.2016.00009.

Plohl, N., \& Musil, B. (2020, April 8). Modeling compliance with COVID-19 prevention guidelines: The critical role of trust in science. PsyArXiv. https://doi.org/10.31234/osf.io/ $6 a 2 c x$.

Qiu, J., Shen, B., Zhao, M., Wang, Z., Xie, B., \& Zu, Y. (2020). A nationwide survey of psychological distress among Chinese people in the COVID-19 epidemic: Implications and policy recommendations. General Psychiatry, 33(2), e100213. https://doi.org/10.1136/ gpsych-2020-100213.

Quinn, S. C., Jamison, A., Freimuth, V., An, J., Hancock, G. R., \& Musa, D. (2017). Exploring racial influences on flu vaccine attitudes and behavior: Results of a national survey of White and African American adults. Vaccine, 35(8), 1167-1174. https://doi.org/10.1016/j.vaccine.2016. 12.046.

Rieger, M. O. (2020). What makes young people think positively about social distancing during the corona crisis in Germany? Frontiers in Sociology, 5, 61. https://doi.org/10. 3389/fsoc. 2020.00061 .

Rogers, R. W. (1983). Cognitive and psychological processes in fear appeals and attitudes change: A revised theory of protective motivation. In J. T. Cacioppo \& R. E. Petty (eds.), Social psychophysiology (pp. 153-176). New York, NY: Guilford Press.

Setbon, M., \& Raude, J. (2010). Factors in vaccination intention against the pandemic influenza A/H1N1. European Journal of Public Health, 20(5), 490-494. https://doi.org/ 10.1093/eurpub/ckq054.

Spector, P. E. (1992). Summated rating scale construction: An introduction. London: Sage.

Šrol, J., Mikušková, E. B., \& Cavojova, V. (2020, March 31). When we are worried, what are we thinking? Anxiety, lack of control, and conspiracy beliefs amidst the COVID-19 pandemic. PsyArXiv. https://doi.org/10.31234/osf.io/ f9e6p. 
Ståhl, T., \& van Prooijen, J.-W. (2018). Epistemic rationality: Skepticism toward unfounded beliefs requires sufficient cognitive ability and motivation to be rational. Personality and Individual Differences, 122, 155-163. https://doi.org/10.1016/j.paid.2017.10.026.

Stanley, M. L., Barr, N., Peters, K., \& Seli, P. (2021). Analytic-thinking predicts hoax beliefs and helping behaviors in response to the COVID-19 pandemic. Thinking \& Reasoning. Advanced online publication. https://doi.org/10. 1080/13546783.2020.1813806.

Stieger, S., Gumhalter, N., Tran, U. S., Voracek, M., \& Swami, V. (2013). Girl in the cellar: A repeated crosssectional investigation of belief in conspiracy theories about the kidnapping of Natascha Kampusch. Frontiers in Psychology, 4, 297. https://doi.org/fpsyg.2013.00297.

Swami, V., Barron, D., Weis, L., Voracek, M., Stieger, S., \& Furnham, A. (2017). An examination of the factorial and convergent validity of four measures of conspiracist ideation, with recommendations for researchers. PLoS ONE, 12(2), e0172617. https://doi.org/10.1371/journal.pone. 0172617.

Swami, V., Coles, R., Stieger, S., Pietschnig, J., Furnham, A., Rehim, S., \& Voracek, M. (2011). Conspiracist ideation in Britain and Austria: Evidence of a monological belief system and associations between individual psychological differences and real-world and fictitious conspiracy theories. British Journal of Psychology, 102(3), 443-463. https://doi.org/10.1111/j.2044-8295.2010.02004.x.

Swami, V., \& Furnham, A. (2014). Political paranoia and conspiracy theories. In J.-P. Prooijen, \& P. A. M. van Lange (eds.), Power politics, and paranoia: Why people are suspicious of their leaders (pp. 218-236). Cambridge: Cambridge University Press.

Swami, V., Pietschnig, J., Tran, U. S., Nader, I. W., Stieger, S., \& Voracek, M. (2013). Lunar lies: The impact of informational framing and individual differences in shaping conspiracist beliefs about the moon landings. Applied Cognitive Psychology, 27(1), 71-80. https://doi.org/10. 1002/acp. 2873.

Swami, V., Voracek, M., Stieger, S., Tran, U. S., \& Furnham, A. (2014). Analytic thinking reduces belief in conspiracy theories. Cognition, 133(3), 572-585. https://doi.org/10. 1016/j.cognition.2014.08.006.

Tabachnik, B. G., \& Fidell, L. S. (2007). Using multivariate statistics (5th ed.). New York, NY: Pearson.
Teovanović, P., Lukić, P., Zupan, Z., Lazić, Ninković, \& Žeželi, I. (2021). Irrational beliefs differentially predict adherence to guidelines and pseudoscientific practices during the COVID-19 pandemic. Applied Cognitive Psychology, 35(2), 486-496. https://doi.org/10.1002/acp. 3770 .

Torales, J., O’Higgins, M., Castaldelli-Maia, J. M., \& Ventriglio, A. (2020). The outbreak of COVID-19 coronavirus and its impact on global mental health. International Journal of Social Psychiatry. Advanced online publication. https://doi.org/10.1177/ 0020764020915212.

van Prooijen, J.-W. (2017). Why education predicts decreased belief in conspiracy theories. Applied Cognitive Psychology, 31(1), https://doi.org/10.1002/acp.3301.

Velicer, W. F., Eaton, C. A., \& Fava, J. L. (2000). Construct explication through factor or component analysis: A review and evaluation of alternative procedures for determining the number of factors or components. In R. D. Goffin \& E. Helmes (eds.), Problems and solutions in human assessment: Honoring Douglas N. Jackson at seventy (pp. 47-71). Utrecht: Kluwer Academic.

Waterson, J., \& Hern, A. (2020, April 7). How false claims about $5 \mathrm{G}$ health risks spread into the mainstream. The Guardian. https://www.theguardian.com/technology/ 2020/apr/07/how-false-claims-about-5g-health-risksspread-into-the-mainstream.

Wiederhold, B. K. (2020). Social media use during social distancing. Cyberpsychology, Behavior, and Social Networking. Advanced online publication. https://doi. org/10.1089/cyber.2020.29181.bkw.

Wise, T., Zbozinek, T., Michelini, G., Hagan, C. C., \& Mobbs, D. (2020, March 19). Changes in risk perception and protective behaviour during the first week of the COVID-19 pandemic in the United States. PsyArXiv. https://doi.org/10.31234/osf.io/dz428.

Worthington, R., \& Whittaker, T. (2006). Scale development research: A content analysis and recommendations for best practice. Counseling Psychologist, 34(6), 806-838. https://doi.org/10.1177/0011000006288127.

Zhang, X., Wang, F., Zhu, C., \& Wang, Z. (2020). Willingness to self-isolate when facing a pandemic risk: Model, empirical test, and policy recommendations. International Journal of Environmental Research and Public Health, 17(1), 197. https://doi.org/10.3390/ijerph 17010197. 